\title{
Impaired Endocardial Radial Strain in Hypertensive Patients with Electrocardiographic Strain Pattern on Two- dimensional Speckle-Tracking Echocardiography
}

Yoshikazu Ohara*, Yuki Yoshimura, Yohko Fukuoka, and Katsuhito Yamamoto

Division of Cardiology, Kochi Health Sciences Center, 2125-1 Ike, Kochi 781-8555, Japan

Received: November 09, 2013; Accepted: August 23, 2014, Published: September 08, 2014

*Corresponding author: Yoshikazu Ohara, Division of Cardiology, Kochi Health Sciences Center, 2125-1 Ike, Kochi 781-8555, Japan, Tel: +81-888373000; Fax: +81-88837-6766; E-mail: yosikazu_ohara@khsc.or.jp

\begin{abstract}
Background: Strain ST-T changes on Electrocardiography (ECG) is a well-recognized marker of the presence and severity of Left Ventricular (LV) hypertrophy, which is usually associated with subendocardial dysfunction. However, the relationship between ST-T change and subendocardial dysfunction in hypertensive patients is unknown. Recently, two-dimensional speckle-tracking echocardiography has been used to define myocardial deformation parameters of the LV segment. Herein, we assessed subendocardial dysfunction patients with strain ST-T changes on electrocardiogram using two-dimensional speckle-tracking echocardiography.

Methods: Parasternal short-axis and apical long-axis views of the LV were acquired in 42 controls and 69 essential hypertensive patients. Patients were divided into two groups according to presence $(n=29)$ or absence $(n=40)$ of strain ST-T changes. Radial, circumferential and longitudinal strain in subendocardial and subepicardial layers were calculated.

Results: No significant intergroup differences in circumferential strain in the subendocardial and subepicardial layers were observed. Longitudinal strain was decreased in hypertensive patients with strain ST-T changes versus patients without strain ST-T changes or control subjects (antero-septal: $p<0.0001$; posterior: $p<0.005$ ). Although epicardial radial strain was similar between patients with and without strain ST-T changes, endocardial radial strain was reduced in strain ST-T change group versus the no ST-T change group (antero-septal : $19.3 \pm 14.5$ vs. $31.9 \pm 15.8, p<0.01$; posterior : $25.4 \pm 14.9$ vs. $34.5 \pm 11.4, p<0.05$ ).

Conclusions: Hypertensive patients with strain ST-T changes exhibit impaired longitudinal strain and endocardial radial strain, with preserved circumferential strain and epicardial radial strain. The impairment of endocardial radial strain in hypertensive patients with strain ST-T changes suggests a possible link between strain ST-T changes and subendocardial dysfunction.
\end{abstract}

Keywords: Left Ventricular Hypertrophy; Strain ST-T change; Two-dimensional speckle tracking echocardiography

\section{Abbreviations}

ECG: Electrocardiogram; LV: Left Ventricular; LVH: Left Ventricular Hypertrophy; EF: Ejection Fraction; E: Early diastolic transmitral velocity; A: Late diastolic transmitral velocity; Ea: Early diastolic velocity; Aa: Late diastolic velocity

\section{Background}

The strain pattern of ST depression and T-wave inversion on the surface 12-lead Electrocardiogram (ECG) is a well-recognized marker of the presence and severity of anatomic Left Ventricular Hypertrophy (LVH) [1-3]. Strain ST-T changes are also associated with adverse prognosis in several clinical conditions $[4,5]$. Therefore, detection of subtle changes in LV contractile dysfunction at an early subclinical stage has important clinical implications.

Recent improvement in 2-dimensional echocardiographic image resolution has enabled detection of tissue pixels and tracking of acoustic markers from frame-to-frame [6-8]. Assessment of radial, circumferential, and longitudinal strain from tissue pixel tracing systems based on echocardiographic images has been reported [7]. In the present study, we used an advanced technique that allowed analysis of myocardial deformation based on speckle tracking separately within the endocardial and epicardial layers of the myocardium. The aim of this study was to assess the strain in the subendocardial and subepicardial layers in patients with strain ST-T changes on ECG using two-dimensional speckle-tracking echocardiography.

\section{Methods}

\section{Study population}

Our study population consisted of 75 hypertensive patients with normal LV ejection fraction and 45 controls subjects collected from April 2011 to November 2011. A total of 42 control subjects were matched for age, sex, and body mass index. All control subjects had coronary risk factors but no overt cardiac disease. 
Hypertension was defined as systolic blood pressure $\geq 140$ $\mathrm{mmHg}$ and/or diastolic blood pressure $\geq 90 \mathrm{mmHg}$ or receiving treatment with antihypertensive drugs. Patients with myocardial infarction, atrial fibrillation, heart-valve disease were excluded. Six patients were excluded because of poor echocardiograms. The remaining 69 hypertensive patients were enrolled. All patients gave written informed consent to participate in the study, which was approved by the regional ethics committees.

\section{Electrocardiography}

The ECGs were recorded at $25 \mathrm{~mm} / \mathrm{s}$ and $1 \mathrm{mV} / \mathrm{cm}$ calibration. Electrocardiographic strain was defined as a down sloping convex ST-segment depression combined with an inverted asymmetrical T-wave with polarity opposite to the main QRS deflection in leads V5 and/or V6. No specific magnitude of ST-segment depression was required for the diagnosis of ECG strain. Patients were divided into two groups according to the presence $(n=29)$ or absence $(n=40)$ of strain ST-T changes.

\section{Echocardiography}

Echocardiographic studies were performed using a standard commercial ultrasound machine (iE33; Philips, Andover, MA USA) with a phased-array transducer. Single cine loops were recorded from two standard apical planes consisting of 4-chamber and 2-chamber views. LV end-diastolic volume, LV end-systolic volume, and Ejection Fraction (EF) were determined from apical 2 -chamber and 4-chamber views using the modified Simpson's method. All tracing of the endocardial borders was performed manually three times, and the measurements were averaged. LV mass was calculated using the formula proposed by Devereux et al. [9] and corrected by the body surface areas to derive LV mass index. The early diastolic transmitral velocity (E) and late diastolic transmitral velocity (A) were recorded in the apical 4-chamber view with the sample volume $(5 \mathrm{~mm})$ positioned in the direction of antegrade flow at the level of the mitral valve tips in diastole. The early diastolic velocity (Ea) and late diastolic velocity $(\mathrm{Aa})$ of the mitral annulus in the 4 -chamber view were measured. Ea and Aa were obtained at the septal and lateral sites of the annulus, and average values of these measurements were calculated for each patient.

\section{Strain analysis with speckle-tracking imaging}

Two-dimensional B-mode grayscale images were captured with a frame rate of $50-80 \mathrm{fps}$, and at least three beats were recorded for analysis. Offline analyses of the short-axis view at the mid-papillary level and apical long-axis view were performed using dedicated software that tracked the changes in 2-dimensional speckle position on a frame to frame basis throughout the cardiac cycle (QLab 6.0; Philips). When a cardiac cycle with a good quality image was selected, a region of interest for speckle tracking was initially defined at end-diastole using a semi-automated border detection method. Strain analysis was performed as described previously [10]. The locations of the 18 tracking points were then adjusted when necessary so that the region of interest extended from endocardial to epicardial borders to approximate the myocardium, which was divided into subendocardial and subepicardial layers of equal thickness. Data were then automatically processed by the system and myocardial strain curves were generated for both layers. If the tracking was not satisfactory, manual adjustments were made to the tracking points. If satisfactory tracking was not accomplished within 5 min, the non-tracking segments were excluded from analysis. Epicardial and endocardial strain were calculated by data derived from all layers. Radial, circumferential, and longitudinal strain in the subendocardial and subepicardial layers at the posterior and anteroseptal segments were also measured (Figure 1). All variables in this study represent the mean value of measurements taken in three consecutive cardiac cycles.

\section{Statistics}

Data are expressed as mean \pm standard deviation. Comparisons of continuous variables among the three groups were performed using one-way analysis variance and post-hoc Bonferroni analysis. Categorical variables were compared using Fisher's exact test or chi-square test whenever appropriate. The correlation between LV mass index and endocardial radial strain was assessed by simple linear regression analysis. We assessed the interobserver and intraobserver variability for strain measurements from 15 randomly selected patients. Intraobserver variability of endocardial radial, circumferential, and longitudinal strain at the posterior segments was $3.3 \pm 2.4 \%$, $4.2 \pm 3.1 \%$, and $5.6 \pm 4.9 \%$, respectively. Interobserver variability of endocardial radial, circumferential, and longitudinal strain at the posterior segments was $3.7 \pm 2.6 \%, 5.3 \pm 4.7 \%$, and 7.1 $\pm 5.9 \%$, respectively. For all analyses, a $\mathrm{p}$ value $<0.05$ was considered significant.

\section{Results}

\section{Baseline characteristics and echocardiographic measurements}

Table 1 lists the baseline clinical characteristics of all subjects. There were no significant differences in age, sex, history of diabetes, and dyslipidemia between the three groups. Table
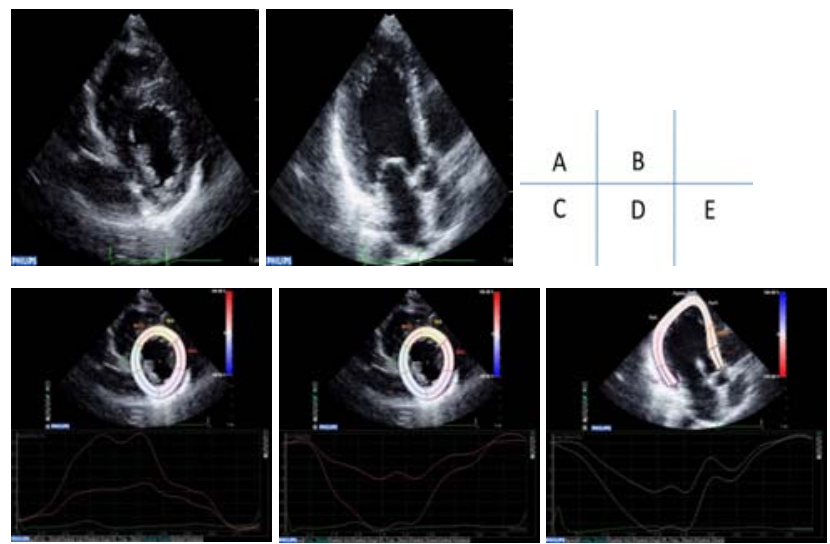

Figure 1: Assessment of left ventricular myocardial strain patterns using 2-D speckle-tracking strain imaging. The mid-papillary short axis view (A) and apical long axis view (B) of the left ventricle were acquired. Radial strain (C) and circumferential strain (D) are measured from the mid-papillary short axis views. Longitudinal strain (E) is measured from the apical long axis view. Examples of strain profiles were measured at the posterior segments. 
2 shows echocardiographic characteristics of all subjects. LVEF, $\mathrm{LV}$ end-diastolic volume, and LV end-systolic volume were not significantly different between the three groups. LV mass index was significantly greater in the strain group than in the nonstrain and control groups $(p<0.0001)$. E/Ea was significantly greater in the strain group than in the non-strain and control groups $(p<0.001)$.

\section{Strain measurements}

From a total of 444 analyzed segments, 26 posterior segments and 16 anteroseptal segments were excluded owing to suboptimal myocardial tracking and poor image quality. Circumferential strain and epicardial radial strain were not significantly different between the three groups (Table 3). Longitudinal strain at both the posterior and anteroseptal segments was significantly decreased in the strain group compared with the non-strain and control groups. Epicardial radial strain was similar between patients with and without strain ST-T changes, while endocardial radial strain was significantly reduced in the strain group compared with the non-strain group (antero-septal: $19.3 \pm 14.5$ vs. $31.9 \pm 15.8, \mathrm{p}<0.01$; posterior: $25.4 \pm 14.9$ vs. $34.5 \pm 11.4, \mathrm{p}<$ $0.05)$. Figure 2 shows a typical radial strain in a patient with and without strain ST-T changes.

\section{Relationship between strain and LV mass}

In the hypertensive patients, endocardial radial strain at the posterior segment was significantly correlated with the LV mass index ( $r=0.36, p<0.005$ ) (Figure 3). Similarly, endocardial strain at the anteroseptal segment was significantly correlated with the LV mass index ( $r=0.39, p<0.001)$ (Figure 3). However, in the control group, endocardial strain in the posterior and anteroseptal segments was not significantly correlated with the LV mass index (posterior: $r=0.09, p=0.56$; antero-septal: $r=0.02, p$ $=0.90$ ) (Figure 3).

\section{Discussion}

The present study showed that longitudinal strain and endocardial radial strain was decreased in patients with strain ST-T changes on ECG.

Table 1: Clinical characteristics

\begin{tabular}{|c|c|c|c|}
\hline & \multirow[b]{2}{*}{$\begin{array}{c}\text { Controls } \\
(N=42)\end{array}$} & \multicolumn{2}{|c|}{ Hypertensive patients } \\
\hline & & $\begin{array}{l}\text { Strain } \\
\text { group (N } \\
=29)\end{array}$ & $\begin{array}{c}\text { Non-strain } \\
\text { group }(\mathrm{N}= \\
40)\end{array}$ \\
\hline Age (yrs) & $70 \pm 20$ & $70 \pm 11$ & $74 \pm 7$ \\
\hline Male & $\begin{array}{c}20 \\
(47 \%)\end{array}$ & $15(51 \%)$ & $18(45 \%)$ \\
\hline Body mass index $\left(\mathrm{kg} / \mathrm{m}^{2}\right)$ & $\begin{array}{c}21.9 \pm \\
2.7\end{array}$ & $22.4 \pm 3.4$ & $22.9 \pm 2.6$ \\
\hline Diabetes mellitus & $0(0 \%)$ & $1(3 \%)$ & $4(10 \%)$ \\
\hline Dyslipidemia & $0(0 \%)$ & $7(24 \%)$ & $12(30 \%)$ \\
\hline \multicolumn{4}{|l|}{ Medications } \\
\hline Ca channel antagonist & $0(0 \%)$ & $16(55 \%)$ & $22(55 \%)$ \\
\hline $\begin{array}{l}\text { Angiotensin-converting enzyme } \\
\text { inhibitor/Angiotension receptor } \\
\text { blocker }\end{array}$ & $0(0 \%)$ & $19(66 \%)$ & $24(60 \%)$ \\
\hline Beta-blocker & $0(0 \%)$ & $9(31 \%)$ & $9(22 \%)$ \\
\hline
\end{tabular}

$\mathrm{P}=\mathrm{NS}$.
Table 2: Echocardiographic

\begin{tabular}{|c|c|c|c|c|}
\hline & \multirow{2}{*}{$\begin{array}{l}\text { Controls } \\
(N=42)\end{array}$} & \multicolumn{2}{|c|}{ Hypertensive patients } & \multirow{2}{*}{$\begin{array}{l}\text { P-value } \\
\text { (ANOVA) }\end{array}$} \\
\hline & & $\begin{array}{c}\text { Strain group } \\
(N=29)\end{array}$ & $\begin{array}{c}\text { Non-strain } \\
\text { group }(N=40)\end{array}$ & \\
\hline $\begin{array}{l}\text { LV end-diastolic } \\
\text { volume }(\mathrm{ml})\end{array}$ & $92 \pm 32$ & $92 \pm 35$ & $84 \pm 23$ & NS \\
\hline $\begin{array}{l}\text { LV end-systolic } \\
\text { volume (ml) }\end{array}$ & $34 \pm 15$ & $38 \pm 20$ & $32 \pm 11$ & NS \\
\hline $\begin{array}{l}\text { LV ejection } \\
\text { fraction }(\%)\end{array}$ & $65 \pm 7$ & $60 \pm 9$ & $62 \pm 8$ & NS \\
\hline $\begin{array}{l}\text { LV mass index } \\
\left(\mathrm{g} / \mathrm{m}^{2}\right)\end{array}$ & $102 \pm 20$ & $181 \pm 68$ & $127 \pm 29$ & $<0.0001$ \\
\hline $\begin{array}{l}\text { E velocity } \\
(\mathrm{cm} / \mathrm{s})\end{array}$ & $90 \pm 29$ & $97 \pm 35$ & $92 \pm 31$ & NS \\
\hline $\begin{array}{l}\text { A velocity } \\
(\mathrm{cm} / \mathrm{s})\end{array}$ & $78 \pm 30$ & $107 \pm 42$ & $103 \pm 31$ & $<0.005$ \\
\hline $\mathrm{E} / \mathrm{A}$ & $1.2 \pm 0.5$ & $1.0 \pm 0.5$ & $0.9 \pm 0.4$ & NS \\
\hline Ea $(\mathrm{cm} / \mathrm{s})$ & $7.8 \pm 2.9$ & $4.6 \pm 1.4$ & $6.2 \pm 1.8$ & $<0.0001$ \\
\hline Aa $(\mathrm{cm} / \mathrm{s})$ & $9.6 \pm 7.0$ & $7.4 \pm 1.5$ & $8.4 \pm 1.6$ & NS \\
\hline $\mathrm{E} / \mathrm{Ea}$ & $12.4 \pm 6.7$ & $23.8 \pm 12.6$ & $16.2 \pm 7.4$ & $<0.0001$ \\
\hline
\end{tabular}

characteristics.

Table 3: Parameters of strain measurements.

\begin{tabular}{|c|c|c|c|c|}
\hline & \multirow[b]{2}{*}{$\begin{array}{l}\text { Controls } \\
(N=42)\end{array}$} & \multicolumn{2}{|c|}{ Hypertensive patients } & \multirow[b]{2}{*}{$\begin{array}{l}\text { P-value } \\
\text { (ANOVA) }\end{array}$} \\
\hline & & $\begin{array}{c}\text { Strain } \\
\text { group }(N= \\
29)\end{array}$ & $\begin{array}{c}\text { Non-strain } \\
\text { group }(\mathrm{N}= \\
40)\end{array}$ & \\
\hline \multicolumn{5}{|l|}{ Posterior segment } \\
\hline \multicolumn{5}{|l|}{ Endocardial layer } \\
\hline Radial strain (\%) & $34.4 \pm 15.8$ & $25.4 \pm 14.9^{*}$ & $34.5 \pm 11.4^{\S}$ & $<0.05$ \\
\hline $\begin{array}{l}\text { Circumferential } \\
\text { strain (\%) }\end{array}$ & $-23.9 \pm 7.1$ & $-20.7 \pm 5.3$ & $-23.0 \pm 6.6$ & NS \\
\hline $\begin{array}{l}\text { Longitudinal strain } \\
(\%)\end{array}$ & $-18.3 \pm 6.1$ & $-13.2 \pm 6.9^{*}$ & $-19.1 \pm 8.3^{\pi}$ & $<0.005$ \\
\hline \multicolumn{5}{|l|}{ Epicardial layer } \\
\hline Radial strain (\%) & $26.6 \pm 12.5$ & $27.8 \pm 13.4$ & $29.2 \pm 10.6$ & NS \\
\hline $\begin{array}{l}\text { Circumferential } \\
\text { strain (\%) }\end{array}$ & $-17.6 \pm 4.5$ & $-14.7 \pm 4.3$ & $-14.9 \pm 5.8$ & NS \\
\hline $\begin{array}{l}\text { Longitudinal strain } \\
(\%)\end{array}$ & $-17.3 \pm 6.3$ & $-11.5 \pm 4.7^{\dagger}$ & $-16.7 \pm 8.0^{\S}$ & $<0.005$ \\
\hline \multicolumn{5}{|l|}{$\begin{array}{l}\text { Antero-septal } \\
\text { segment }\end{array}$} \\
\hline \multicolumn{5}{|l|}{ Endocardial layer } \\
\hline Radial strain (\%) & $32.0 \pm 17.7$ & $19.3 \pm 14.5^{\dagger}$ & $31.9 \pm 15.8 \pi$ & $<0.005$ \\
\hline $\begin{array}{l}\text { Circumferential } \\
\text { strain (\%) }\end{array}$ & $-23.9 \pm 7.1$ & $-20.7 \pm 5.2$ & $-23.0 \pm 6.6$ & NS \\
\hline $\begin{array}{l}\text { Longitudinal strain } \\
(\%)\end{array}$ & $-19.2 \pm 6.1$ & $-13.1 \pm 4.3^{\ddagger}$ & $-18.3 \pm 5.1^{\pi}$ & $<0.0001$ \\
\hline \multicolumn{5}{|l|}{ Epicardial layer } \\
\hline Radial strain (\%) & $27.1 \pm 13.8$ & $20.7 \pm 11.6$ & $28.6 \pm 18.5$ & NS \\
\hline $\begin{array}{l}\text { Circumferential } \\
\text { strain }(\%)\end{array}$ & $-14.5 \pm 4.5$ & $-13.5 \pm 5.7$ & $-14.5 \pm 4.4$ & NS \\
\hline $\begin{array}{l}\text { Longitudinal strain } \\
(\%)\end{array}$ & $-17.3 \pm 6.3$ & $-11.5 \pm 4.7^{\ddagger}$ & $-16.7 \pm 8.0 \pi$ & $<0.0001$ \\
\hline
\end{tabular}

${ }^{*} \mathrm{p}<0.05$ vs. controls; $\uparrow \mathrm{p}<0.005$ vs. controls; $\ddagger \mathrm{p}<0.0001$ vs. controls; $\S$ $\mathrm{p}<0.05$ vs. strain group; $\mathbb{1} \mathrm{p}<0.01$ vs. strain group 

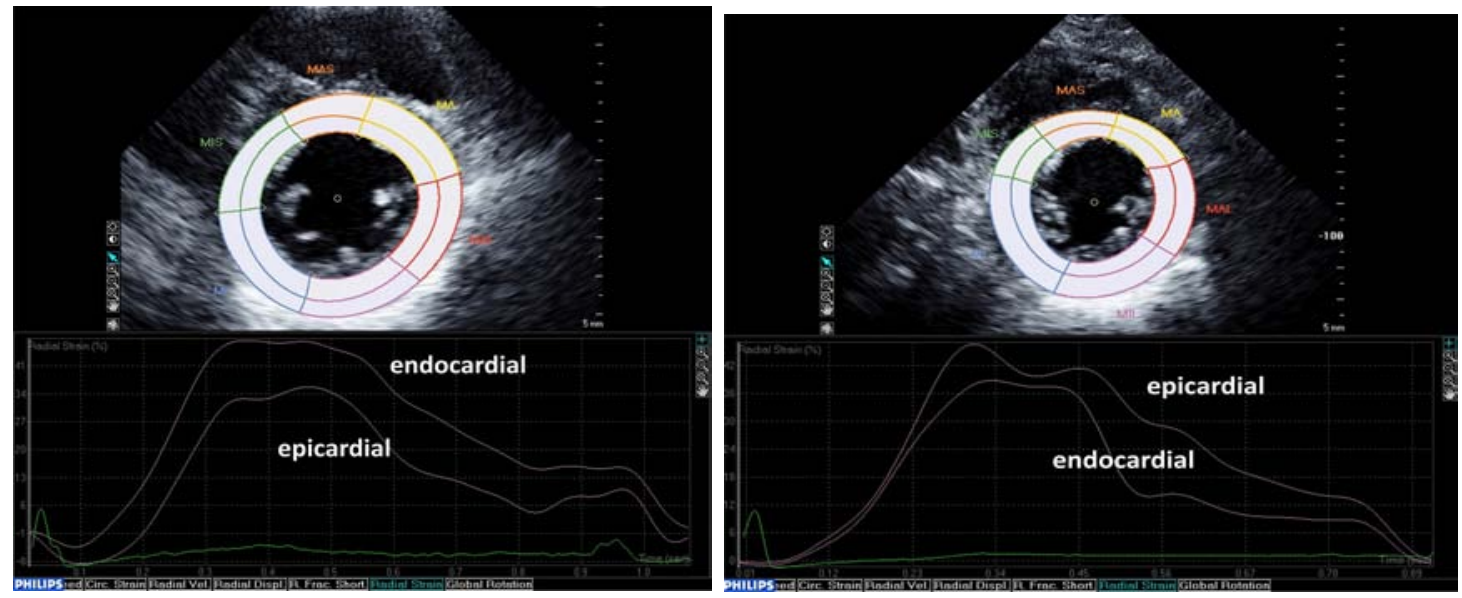

Figure 2: Examples of radial strain profiles at the posterior segment in a hypertensive patient with strain ST-T change (left) and without strain ST-T change (right).

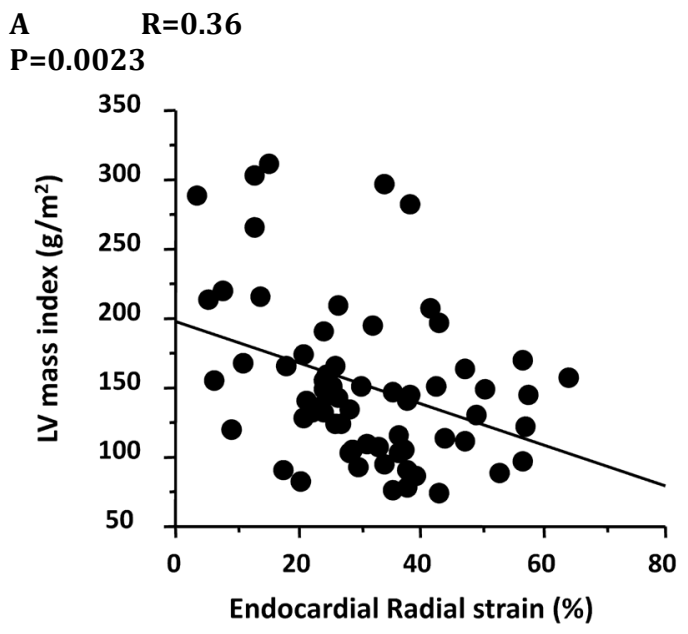

$\begin{array}{ll}C & R=0.09 \\ P=0.56 & \end{array}$

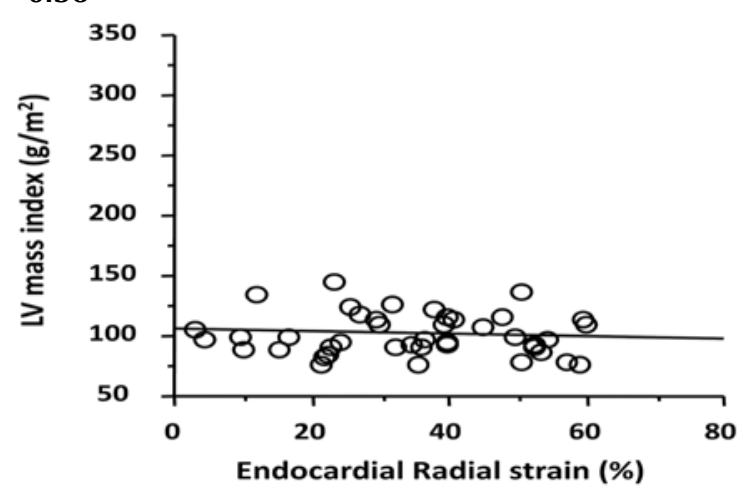

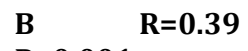

$\mathbf{P}=\mathbf{0 . 0 0 1}$

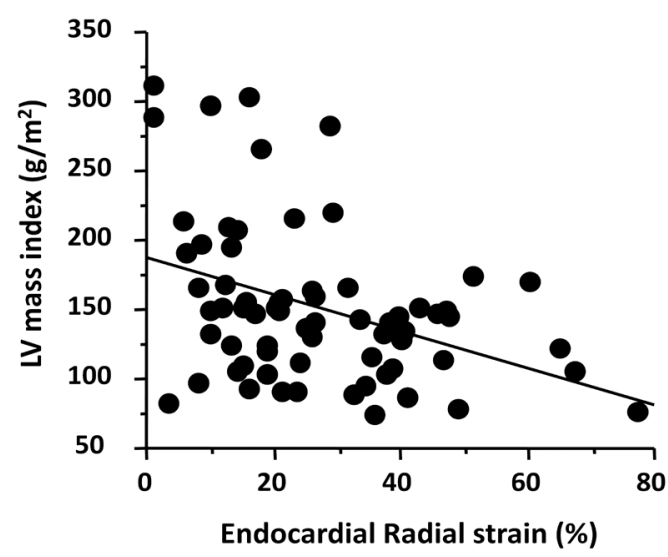

D $\quad \mathbf{R}=\mathbf{0 . 0 2}$

$\mathbf{P}=\mathbf{0 . 9 0}$

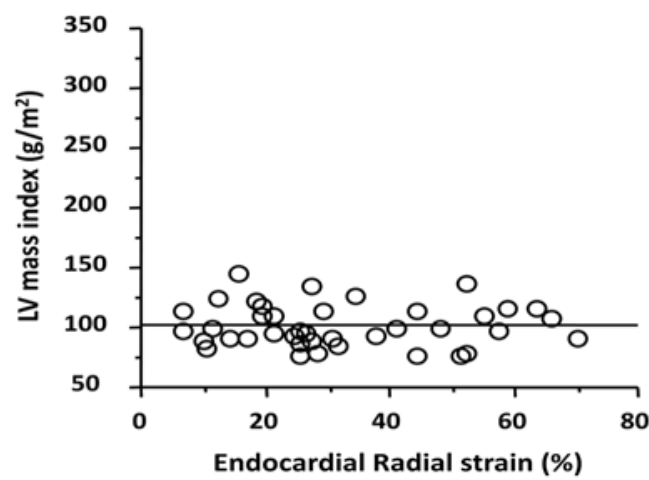

Figure 3: Correlation between the left ventricular mass index and endocardial radial strain. Endocardial radial strain at the posterior (A) and anteroseptal (B) segments in the strain ST-T changes group were significantly correlated with the left ventricular mass index. Endocardial radial strain at the posterior (C) and antero-septal (D) segments in the no strain ST-T changes group were not significantly correlated with the left ventricular mass index.

Citation: Ohara Y, Yoshimura Y, Fukuoka Y, Yamamoto K (2014) Impaired Endocardial Radial Strain in Hypertensive Patients with Electrocardiographic Strain Pattern on Two-dimensional Speckle-Tracking Echocardiography. J Clin Trial Cardiol 1(2): 1-6. DOI: 
In general, subendocardial longitudinal fibers are vulnerable in the presence of myocardial ischemia and hemodynamic overload, and abnormal longitudinal function can be detected at an early stage [11,12]. Recent studies using speckletracking echocardiography have reported that LV contraction is first impaired in the longitudinal direction in patients with cardiovascular risk factors [13-16]. Therefore, strain is a measure reflecting regional systolic function and has been used to detect subclinical myocardial dysfunction in a number of cardiac conditions. However, the ECG strain pattern identified in subjects at increased cardiovascular risk, the mechanisms remain unclear.

In hypertensive subjects, ST segments depression with T-wave inversion may reflect an increased LVM independent of the presence of coronary artery disease [4]. The amplitude of the $\mathrm{T}$ wave was attributed to the square of the cell radius, while the inversion or flattening of the $\mathrm{T}$ wave was attributed to the contiguity of myocardial layers with different durations of the action potential [17]. In addition to increased LVM, the strain pattern may be a marker of subendocardial myocardial ischemia, without coronary artery disease. Despite the increased diameter of coronary arteries in hypertrophied hearts, some predisposition to ischemia may exist, particularly in the subendocardial layers [18]. In the present study, endocardial radial strain was significantly correlated with the LVM index in hypertensive patients. Moreover, LVM index was significantly greater in patients with strain ST-T changes compared with those without strain ST-T changes. On the other hand, at the same stage, this phenomenon may not be present in mid-myocardial fiber layers, resulting in normal circumferential strain. In the current study, circumferential strain was not different in hypertensive patients with and without strain ST-T change. Moreover, circumferential function might be preserved until global LV dysfunction develops, suggesting that that the assessment of circumferential strain might be less sensitive to detect subclinical LV dysfunction.

Nishikage et al. [19] reported that regional longitudinal strain was reduced in patients with strain ST-T change. However, in this study, we measured the layer-specific myocardium strains. To the best of our knowledge, there are few studies of layerspecific strain analysis in patients with strain ST-T changes. Layer-specific analysis of myocardial function based on advanced echocardiographic speckle tracking techniques is a promising tool to obtain quantitative insights into layer-specific myocardial function analysis. Importantly, we found significantly decreased endocardial radial strain in the patients with strain ST-T changes compared with those without strain ST-T changes or control group subjects, although there was a similar circumferential strain. Myocardial heterogeneity is characterized by a significantly higher deformation rate and deformation amplitude in the subendocardial layer compared with the subepicardial layer $[20,21]$. Previous studies have demonstrated that ventricular wall thickening is not uniform, with a ratio of inner-to outer-half thickening of $\sim 2.0$ to 1.3 in the normal heart [22-24].

The mechanism of $\mathrm{LV}$ wall thickening in the radial direction is also unclear. Myocardial fibers are grouped into lumina 3 to 4 cells thick that are interconnected by an extensive extracellular matrix, and the longitudinal-radial shear of these sheets is likely to be an important mechanism underlying wall thickening $[25,26]$. Moreover, radial thickening is influenced by the complex 3-dimensional fiber rearrangement in the LV wall [27]. In dogs with severe LV hypertrophy, exhaustion of subendocardial blood flow reserve is associated with myocyte necrosis and fibrosis, demonstrating that structural alterations play an important role in the development of heart failure [28]. Poulsen et al. [29] showed that reduced longitudinal strain is associated with increased collagen turnover and degree of myocardial fibrosis in hypertensive patients. We hypothesized that the amount of fibrosis may increase in the endocardial layer in hypertensive patients with strain ST-T change compared with those without strain ST-T changes. As a result, this higher degree of myocardial fibrosis may negatively affect LV performance, resulting in impaired endocardial radial strain in hypertensive patients with strain ST-T change.

\section{Clinical implications}

The current study demonstrated that the endocardial radial strain is clinically useful for detecting systolic dysfunction, which cannot be determined using conventional LVEF. Detection of intrinsic systolic dysfunction may aid in the prediction of subsequent morbidity and mortality in patients with strain ST-T changes on ECG. Further, endocardial radial strain may be clinically useful for examining improvement in intrinsic systolic dysfunction by medical treatment.

\section{Limitations}

Several limitations of the present study should be considered. First, we assessed myocardial strain at the mid antero-septal and posterior walls. Therefore, these results may not apply to the other LV segments. Second, the study population was heterogeneous including subjects with or without coronary artery disease. Although we excluded patients with evidence of coronary artery disease as indicated by electrocardiography and conventional echocardiography, and none of the study subjects complained of typical symptoms, the possibility that a small number of subjects with silent myocardial ischemia were included cannot be ruled out because of the lack of confirmation by stress testing or coronary angiography. However, coronary artery disease is a very frequently associated co-morbidity in hypertension, and therefore, our study population reflects clinical daily routine. Third, this study evaluated layer-specific myocardial deformation in hypertensive patients. The layerspecific analysis of myocardial deformation parameters has not been specifically validated in an experimental model. The high spatial resolution of the system allowed separation of the total wall thickness into two separate layers. Moreover, similar accuracy on the layer-specific analysis level can be assumed as for the previously evaluated total wall thickness accuracy.

\section{Conclusions}

Hypertensive patients with strain ST-T changes exhibited impaired longitudinal strain and endocardial radial strain, however circumferential strain and epicardial radial strain were preserved. Strain, especially endocardial radial strain, is useful 
for detection of subtle change of subendocardial dysfunction in hypertensive patients with strain ST-T changes.

\section{References}

1. Devereux RB, Reichek N. Repolarization abnormalities of left ventricular hypertrophy: Clinical, echocardiographic and hemodynamic correlates. Electrocardiol. 1982; 15(1): 47-53.

2. Levy D, Labib SB, Anderson KM, Christiansen JC, Kannel WB, Castell WP. Determinants of sensitivity and specificity of electrocardiographic criteria for left ventricular hypertrophy. Circulation. 1990; 81(3): 815-820.

3. Schillaci G, Verdecchia P, Borgioni C, Ciucci A, Guerrieri M, Zampi I, et al. Improved electrocardiographic diagnosis of left ventricular hypertrophy Am J Cardiol. 1994; 74(7): 714-719.

4. Okin PM, Devereux RB, Nieminen MS, Jern S, Oikarinen L, Viitasalo M, et al. Relationship of the electrocardiographic strain pattern to left ventricular structure and function in hypertensive patients: the LIFE study. Losartan Intervention For End point. J Am Coll Cardiol. 2001; 38(2): 514-520.

5. Lorell BH, Carabello BA. Left ventricular hypertrophy: pathogenesis, detection, and prognosis. Circulation. 2000; 102(4): 470-479.

6. Reisner SA, Lysyansky P, Agmon Y, Mutlak D, Lessick J, Friedman Z. Global longitudinal strain: a novel index of left ventricular systolic function. J Am Soc Echocardiogr. 2004; 17(6): 630-633.

7. Leitman M, Lysyansky P, Sidenko S, Shir V, Peleg E, Binenbaum M, et al. Two-dimensional strain-a novel software for real-time quantitative echocardiographic assessment of myocardial function. J Am Soc Echocardiogr. 2004; 17(10): 1021-1029.

8. Becker M, Bilke E, Kühl H, Katoh M, Kramann R, Franke A, et al. Analysis of myocardial deformation based on pixel tracking in two dimensional echocardiographic images enables quantitative assessment of regional left ventricular function. Heart. 2006; 92(8): 1102-1108.

9. Devereux RB, Alonso DR, Lutas EM, Gottlieb GJ, Campo E, Sachs I, et al Echocardiographic assessment of left ventricular hypertrophy: comparison to necropsy findings. Am J Cardiol.1986; 57(6): 450-458.

10. Zhang Q, Fang F, Liang YJ, Xie JM, Wen YY, Yip GW, et al. A novel multilayer approach of measuring myocardial strain and torsion by $2 \mathrm{D}$ speckle tracking imaging in normal subjects and patients with heart diseases. Int J Cardiol. 2011; 147(1): 32-37. doi: 10.1016/j.ijcard.2009.07.041.

11. Bolognesi R, Tsialtas D, Barilli AL, Manca C, Zeppellini R, Javernaro A, et al. Detection of early abnormalities of left ventricular function by hemodynamic, echo-tissue Doppler imaging, and mitral Doppler flow techniques in patients with coronary artery disease and normal ejection fraction. J Am Soc Echocardiogr. 2001; 14(8): 764-772.

12. Vinereanu D, Khokhar A, Tweddel AC, Cinteza M, Fraser AG. Estimation of global left ventricular function from the velocity of longitudinal shortening. Echocardiography. 2002; 19(3): 177-185.

13. Ng AC, Delgado V, Bertini M, van der Meer RW, Rijzewijk LJ, Shanks $\mathrm{M}$, et al. Findings from left ventricular strain and strain rate imaging in asymptomatic patients with type 2 diabetes mellitus. Am J Cardiol. 2009; 104(10): 1398-1401. doi: 10.1016/j.amjcard.2009.06.063.

14. Mizuguchi Y, Oishi Y, Miyoshi H, Iuchi A, Nagase N, Oki T. The functional role of longitudinal, circumferential, and radial myocardial deformation for regulating the early impairment of left ventricular contraction and relaxation in patients with cardiovascular risk factors: a study with twodimensional strain imaging. J Am Soc Echocardiogr. 2008; 21(10): 1138 1144. doi: 10.1016/j.echo.2008.07.016.
15. Miyoshi H, Mizuguchi Y, Oishi Y, Iuchi A, Nagase N, Ara N, et al. Early detection of abnormal left atrial-left ventricular-arterial coupling in preclinical patients with cardiovascular risk factors: evaluation by twodimensional speckle-tracking echocardiography. Eur J Echocardiogr. 2011; 12(6): 431-439. doi: 10.1093/ejechocard/jer052.

16. Miyoshi H, Oishi Y, Mizuguchi Y, Iuchi A, Nagase N, Ara N, et al. Early predictors of alterations in left atrial structure and function related to left ventricular dysfunction in asymptomatic patients with hypertension. J Am Soc Hypertens. 2013; 7(3): 206-215. doi: 10.1016/j.jash.2013.02.001.

17. Thiry PS, Rosenberg RM, Abbott JA. A mechanism for the electrocardiogram response to left ventricular hypertrophy and acute ischemia. Circ Res. 1975; 36(1): 92-104.

18. Rembert JC, Kleinman LH, Fedor JM, Wechsler AS, Greenfield JC Jr. Myocardial blood flow distribution in concentric left ventricular hypertrophy. J Clin Invest. 1978; 62(2): 379-386. doi: 10.1172/JCI109139.

19. Nishikage T, Takeuchi M, Nakai H, Otsuji Y, Lang RM. Possible link between strain ST-T change on the electrocardiogram and subendocardial dysfunction assessed by two-dimensional speckle-tracking echocardiography. Eur J Echocardiogr. 2010; 11(5): 451-459. doi: 10.1093/ ejechocard/jeq001.

20. Ball RM, Bache RJ, Cobb FR, Greenfield JC Jr. Regional myocardial blood flow during graded treadmill exercise in the dog. J Clin Invest. 1975; 55(1): 43-49. doi: 10.1172/JCI107916.

21. Path G, Robitaille PM, Merkle H, Tristani M, Zhang J, Garwood M, et al. Correlation between transmural high energy phosphate levels and myocardial blood flow in the presence of graded coronary stenosis. Circ Res. 1990; 67(3): 660-673.

22. Cheng A, Nguyen TC, Malinowski M, Daughters GT, Miller DC, Ingels NB Jr. Heterogeneity of left ventricular wall thickening mechanisms. Circulation. 2008; 118(7): 713-721. doi: 10.1161/CIRCULATIONAHA.107.744623.

23. Gallagher KP, Osakada G, Matsuzaki M, Miller M, Kemper WS, Ross J Jr. Nonuniformity of inner and outer systolic wall thickening in conscious dogs. Am J Physiol. 1985; 249(2 Pt 2): H241-248.

24. McCulloch AD, Sung D, Wilson JM, Pavelec RS, Omens JH. Flowfunction relations during graded coronary occlusions in the dog: effects of transmural location and segment orientation. Cardiovasc Res. 199; 37(3): 636-645.

25. LeGrice IJ, Takayama Y, Covell JW. Transverse shear along myocardial cleavage planes provides a mechanism for normal systolic wall thickening. Circ Res. 1995; 77(1): 182-193

26. LeGrice IJ, Smaill BH, Chai LZ, Edgar SG, Gavin JB, Hunter PJ. Laminar structure of the heart: ventricular myocyte arrangement and connective tissue architecture in the dog. Am J Physiol. 1995; 269(2 pt 2): H571-582.

27. Waldman LK, Nosan D, Villarreal F, Covell JW. Relation between transmural deformation and local myofiber direction in canine left ventricle. Circ Res. 1988; 63(3): 550-562.

28. Hittinger L, Shannon RP, Bishop SP, Gelpi RJ, Vatner SF. Subendomyocardial exhaustion of blood flow reserve and increased fibrosis in conscious dogs with heart failure. Circ Res. 1989; 65(4): 971-980.

29. Poulsen SH, Andersen NH, Heickendorff L, Mogensen CE. Relation between plasma amino-terminal propeptide of procollagen type III and left ventricular longitudinal strain in essential hypertension. Heart. 2005; 91(5): 624-629. 